\title{
EVALUASI HASIL INSEMINASI BUATAN DI BALAI PEMBIBITAN TERNAK UNGGUL DAN HIJAUAN PAKAN TERNAK INDRAPURI
}

\author{
Aidilof $^{(1)}$, Sri Rahayu ${ }^{(2)}$, Supriadi $^{(3)}$ \\ ${ }^{1,2,3}$ Program Studi Peternakan Fakultas Pertanian Universitas Jabal Ghafur \\ Email : aidilof@unigha.ac.id
}

\begin{abstract}
ABSTRAK
Peternakan sapi lokal Aceh rata-rata masih berskala kecil dan bersifat tradisional menyebabkan produktivitas ternak rendah. Salah satu cara untuk meningkatkan produktivitas adalah dengan memperbaiki kinerja reproduksi. Inseminasi Buatan merupakan salah satu upaya dalam meningkatkan produktivitas sapi Aceh. Penelitian ini dilaksanakan pada bulan Januari sampai dengan Maret 2019 dengan lokasi penelitian di Balai Pembibitan Ternak Unggul dan Hijauan Pakan Ternak Indrapuri (BPTU-HPT Indrapuri).

Penelitian ini bertujuan untuk mengetahui tingkat keberhasilan Insemiansi Buatan (IB) berdasarkan Service Per Conception (S/C) dan Conception Rate (CR). Data yang digunakan adalah data kuantitatif yang diperoleh dari petugas dan catatan rekording dengan metode observasi dan wawancara kepada petugas dan pejabat yang membidangi inseminasi buatan. Materi yang digunakan adalah sapi aceh yang di-IB pada tahun 2017 sebanyak 19 ekor dan 2018 sebanyak 22 ekor dengan pejantan yang berasal dari sapi aceh.

Berdasarkan hasil analisa menunjukkan bahwa S/C sapi aceh di BPTU-HPT Indrapuri yaitu 1,12 dan CR 89,47\% untuk tahun 2017. Dan untuk tahun 2018 diperoleh nilai S/C 1,16 dan CR 86,36\%. Hasil perhitungan Chi-Square trhadap S/C antara tahun 2017 dan 2018 tidak menunjukkan perbedaan yang nyata $(P \geq 0,05)$. Sedangkan hasil uji $Z$ terhadap $C R$ sapi aceh untuk tahun 2017 dan 2018 juga tidak menunjukkan perbedaan yang nyata antara tahun 2017 dan 2018.Hasil inseminasi buatan pada BPTU-HPT Indrapuri ini sangat baik bila dibandingkan dengan rata-rata normal S/C yaitu 1,6 - 2,0 dan CR yaitu 60-70 persen.
\end{abstract}

\section{Kata kunci : Inseminasi Buatan, Service Per Conception, Conception Rate}

\section{PENDAHULUAN}

Pembangunan

sub-sektor peternakan di Indonesia perlu ditingkatkan, hal ini mengingat permintaan akan produk peternakan di Indonesia pada umumnya cenderung meningkat dari tahun ke tahun. Hal ini sejalan dengan meningkatnya kesadaran akan kebutuhan gizi masyarakat, akan tetapi tidak diimbangi dengan peningkatan populasi ternak. Oleh sebab itu, perlu adanya usaha peningkatan produksi dan populasi ternak sapipotong.Salah satu yang dapat ditempuh untuk meningkatkan produksi daging dan anak sapi atau pedet adalah dengan meningkatkan jumlah pemilikan sapi dan mutu genetik ternak. Hal ini dapat dilaksanakan dengan menerapkan inseminasi buatan (IB) pada sapi potong, karena semen yang digunakan terhadap IB berasal dari sapi jantan yang genetiknya baik dan angka service per conception (S/C) yang rata-rata lebih kecil dibandingkan dengan kawin alam. Inseminasi buatan (IB) atau kawin suntik adalah upaya memasukkan semen/mani ke dalam saluran reproduksi hewan betina yang sedang birahi denganbantuan inseminator agar hewan dapat bunting.

Dari definisi ini inseminator berperan sangat besar dalam keberhasilan pelaksanaan IB. Keahlian dan keterampilan 
inseminator dalam akurasi pengenalan birahi, sanitasi alat, penanganan (handling) semen beku, pencairan kembali (thawing) yang benar, serta kemampuan melakukan Inseminasi Buatan akan menentukan keberhasilan. Optimalisasi program IB lebih digalakkan karena program ini memberikan nilai tambah cukup besar bagi sumber pendapatan asli daerah dan bagi peternak berupa meningkatnya populasi dan produktivitas ternak, mempercepat jarak kelahiran ternak, memperoleh keturunan jenis ternak yang unggul sehingga meningkatkan kesejahteraan. Perkawinan dengan cara IB merupakan salah satu alat ampuh yang diciptakan manusia untuk meningkatkan populasi dan produksi ternak baik secara kualitatif maupun kuantitatif (Toelihere, 1981).IB adalah usaha manusia memasukkan sperma ke dalam saluran reproduksi betina dengan menggunakan peralatan khusus. IB dikatakan berhasil bila sapi induk yang dilakukan IB menjadi bunting. Masa bunting/periode kebuntingan sapi (gestation period) yaitu jangka waktu sejak terjadi pembuahan sperma terhadap sel telur sampai anak dilahirkan. Menurut Toelihere (1981) periode kebuntingan sapi berkisar 280 sampai dengan 285 hari. Setelah melahirkan disebut masa kosong sampai sapi yang bersangkutan bunting pada periode berikutnya. Pada dasarnya,kesuksesan suatu program IBtergantung kualitas semen yang digunakan, ketepatanpenempatan spermatozoa pada lokasi yang tepat disaluran reproduksi betina dan pada waktu yang tepatpula, sehingga spermatozoa yang berkualitas baik dapatbertemu dengan sel telur untuk terjadinya pembuahan.Upaya yang dilakukan agar penempatan semen disaluran reproduksi betina dapat dilakukan secara tepatwaktu adalah dengan melaksanakan programsinkronisasi berahi. Balai Pembibitan Ternak Unggul dan Hijauan Pakan Ternak Indrapuri merupakan salah satu pusat pemurnian sapi aceh. Perkawinan yang dilaksanakan di balai ini berupa perkawinan secara alamiah dan melalui inseminasi buatan.Sejauh mana evaluasi hasil inseminasi buatan pada sapi aceh di Balai Pembibitan Ternak Unggul dan Hijauan Pakan Ternak Indrapuri belum banyak diteliti . oleh sebab itu dilakukan penelitian dengan judul evaluasi hasil inseminasi buatan pada sapi aceh di Balai Pembibitan Ternak Unggul dan Hijauan Pakan Ternak Indrapuri dengan tujuan untuk memperoleh gambaran tentang penampilan reproduksi sapi aceh yang diinseminasi buatan berdasarkan S/C dan CR.

\section{METODE PENELITIAN}

Penelitian ini dilakukan di Balai pembibitan Ternak Unggul dan Hijauan Pakan Ternak Indrapuri yang terletak di Desa Reukih Dayah Kecamatan Indrapuri Kabuapten Aceh Besar Propinsi Aceh. Dilaksanakan pada bulan Januari sampai dengan Maret 2019. Materi yang digunakan dalam penelitian ini adalah sapi aceh yang di-IB pada tahun 2017 sebanyak 19 ekor dan pada tahun 2018 sebanyak 22 ekor. Metode yang digunakan dalam penelitian ini adalah observasi yaitu melalui pengamatan langsung di lokasi penelitian yang menerapkan perkawinan secara alami dan insemiasi buatan. Disamping itu juga dilakukan wawancara langsung dengan petugas IB dan pejabat yang menangani kegiatan IB guna memperoleh data berupa catatan kartu IB. Data yang diamati adalah :

1. Service per Conception $(\mathbf{S} / \mathrm{C})$

$$
\begin{aligned}
& S / C=\frac{\text { jumlahstraw yang digunakan }}{\text { jumlaht recipient yang bunting }} \\
& \text { 2. Conception Rate (CR) } \\
& C R=\frac{\text { iumlah reciptent yang busting pada } / B \text { pertama }}{\text { iumlah recipient }} \times 100 \%
\end{aligned}
$$

Data Service per Conception (S/C) yang diperoleh dalam penelitian ini dianalisa dengan menggunakan uji ChiSquare (Sudjana, 1992) dengan persamaan 


$$
X^{2}=\sum \frac{\left(f_{0}-f_{h}\right)^{2}}{f h}
$$

Keterangan :

$X^{2}=$ Chi-square

$f_{0}=$ frequensi yang diambil

$f_{h}=$ frequensi yang diharapkan

Sedangkan untuk data Conception Rate (CR) yang diperoleh dianalisa dengan menggunakan Uji Z (Sudjana, 1992) dengan persamaan

$$
\begin{gathered}
Z=\frac{\left(X_{1} / n_{1}\right)-\left(X_{2} / n_{2}\right)}{\sqrt{p q\left\{\left(1 / n_{1}\right)+\left(1 / n_{2}\right)\right\}}} \\
P=\frac{X_{1}+X_{2}}{n_{1}+n_{2}} \\
q=1-p
\end{gathered}
$$

\section{HASIL DAN PEMBAHASAN Gambaran Umum Lokasi Penelitian}

Balai Pembibitan Ternak Unggul dan Hijauan Pakan Ternak Indrapuri adalah unit pelaksana teknis dibidang peternakan dan kesehatan hewan, yang berada di bawah dan bertanggungjawab kepada Direktur Jenderal Peternakan dan Kesehatan Hewan dan secara teknis dibina oleh Direktur Perbibitan Ternak dan Direktur Pakan, yang mempunyai tugas melaksanakan pemeliharaan, produksi, pemuliaan, pengembangan, penyebaran dan distribusi bibit ternak unggul, khususnya sapi Aceh, serta produksi dan distribusi benih/bibit hijauan pakan ternak. Sapi Aceh merupakan rumpun sapi lokal Indonesia yang mempunyai sebaran asli geografis di Provinsi Aceh dan telah dibudidayakan secara turun temurun sebagai kekayaan sumber daya genetik ternak Indonesia sesuai dengan Surat Keputusan Menteri Pertanian No
2907/Kpts/OT.140/6/2011

Penetapan Rumpun Sapi Aceh.

tentang

BPTU-HPT Indrapuri pertama kali didirikan bernama Balai Pembibitan Ternak dan Hijauan Makanan Ternak (BPT dan HMT) dengan SK Mentan Nomor: 313/Kpts/Org/5/1978 pada tanggal 25 Mei 1978. Selanjutnya pada tahun 2002 berubah dengan adanya SK Mentan No.282/Kpts/TU. 210/4/2002 tanggal 6 April 2002, BPT dan HMT berubah namanya menjadi Balai PembibitanTernak Unggul (BPTU) Sapi Aceh Indrapuri NAD. Dalam perkembangannya, BPTU Sapi Aceh Indrapuri-NAD mengalami perubahan nomenklatur kembali pada tahun 2013 yaitu dengan SK Mentan Nomor: 56/ Permentan/ OT.140/5/2013 tanggal 24 Mei 2013 menjadi Balai Pembibitan Ternak Unggul dan Hijauan Pakan Ternak (BPTU-HPT) Indrapuri. BPTU-HPT Indrapuri berada di Desa Reukih Dayah Kecamatan Indrapuri, Kabupaten Aceh Besar, Provinsi Aceh. Posisinya terletak di daerah yang memiliki topografi berbukit-bukit dan berada pada ketinggian (lebih kurang $30-80$ mdpl). Daerahnya termasuk beriklim panas dengan suhu rata-rata 26,66 derajat Celcius, kelembaban 84,83\% dengan curah hujan rata-rata $1.147 \mathrm{~mm} /$ tahun. Intensitas hari hujan mencapai 98 hari per tahun.

Data ternak sapi Aceh yang dipelihara di BPTU-HPT per 01 Januari 2019 sebanyak 943 ekor, yang menempati lahan seluas 430 ha dengan sertifikat No 1 tahun 1983. Lebih dari $30 \%$ lahan yang ada merupakan daerah perbukitan dan semak belukar, sisanya merupakan kebun rumput. (Profil, Balai Pembibitan Ternak Unggul dan Hijauan Pakan Ternak Indrapuri. 2019) 


\section{Manajemen Pemeliharaan Bibit Sapi}

Aceh di BPTU-HPT Indrapuri

Rata-rata nilai S/C yang diperoleh

\section{Skema Manajemen Pemeliharaan Ternak (Inseminasi Buatan) Di BPTU - HPT Indrapuri}

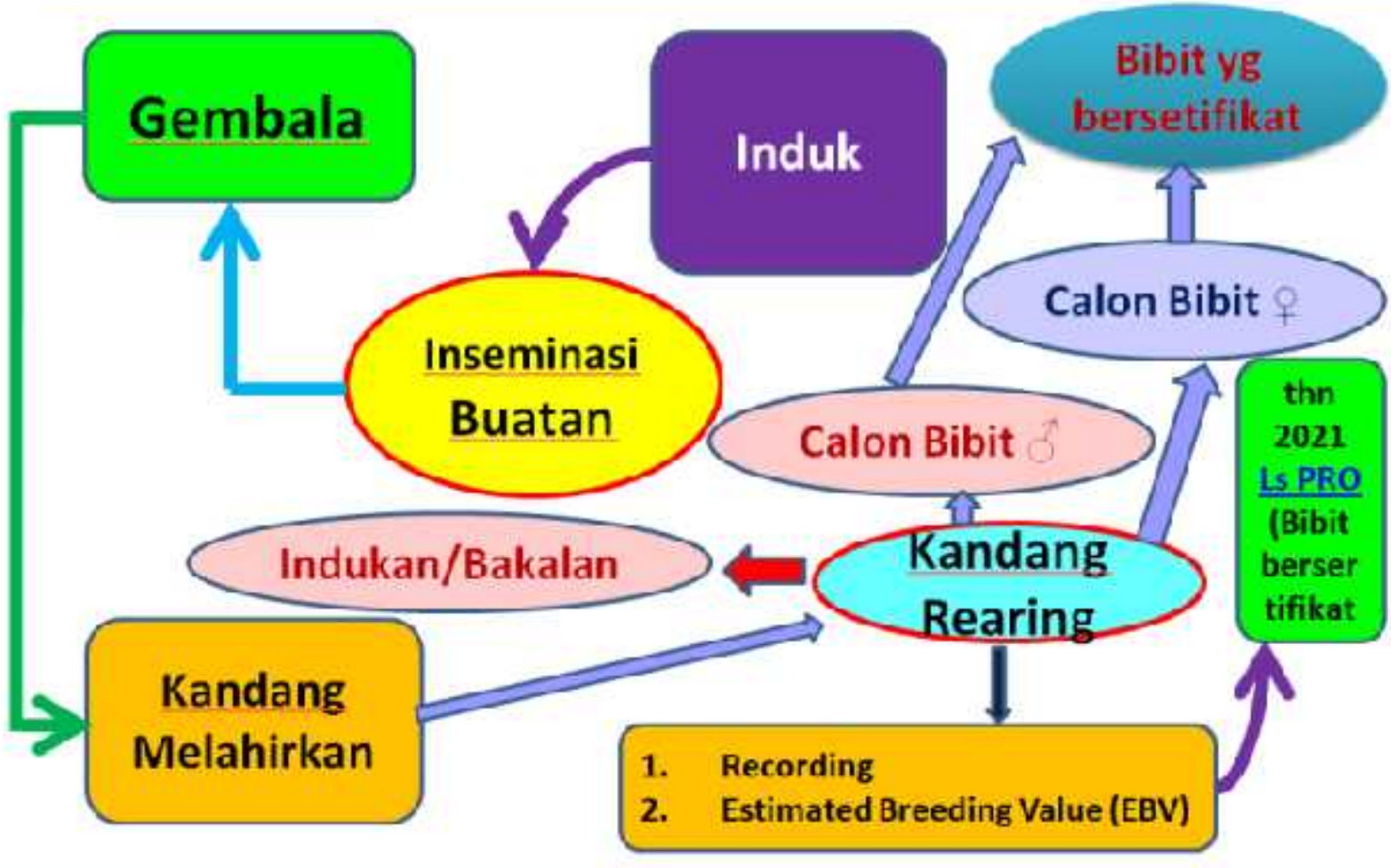

\section{Gambar 1. Skema Manajemen}

Pemeliharaan Ternak ( Inseminasi Buatan )

\section{Servive Per Conception (S/C)}

Service per Conception (S/C) merupakan bilangan yang menunjukkan service atau inseminasi per kebuntingan. Kisaran S/C yang normal adalah 1,6 sampai 2,0. Makin rendah nilai tersebut, makin tinggi kesuburan ternak betina dalam kelompok tersebut, sebaliknya makin tinggi nilai $\mathrm{S} / \mathrm{C}$, maka makin rendah nilai kesuburan ternak betina dalam kelompok tersebut.

Tabel 1. Nilai rata-rata S/C tahun 2017 dan 2018 di BPTU-HPT Indrapuri Service Per Conception

\begin{tabular}{l|c|c|} 
Nilai Rata- & Tahun 2017 & Tahun 2018 \\
\cline { 2 - 3 } Rata & 1,12 & 1,16
\end{tabular}

pada tahun 2017 adalah 1,12 dan pada tahun 2018 adalah 1,16. Dilihat dari angka tersebutmenunjukkan bahwa S/C sapi aceh di BPTU-HPT Indrapuri baik tahun 2017 maupun 2018 adalah rendah. Semakin rendah nilai S/C maka fertilitas sapi semakin tinggi. Menurut Toelihere (1993) bahwa S/C merupakan bilangan yang menunjukkan service atau inseminasi perkebuntingan. Nilai S/C yang normal adalah 1,65 - 2,0 dimana semakin rendah nilai S/C maka semakin tinggi tingkat fertilitas sekelompok ternak. Tabel di atas menunjukkan bahwa S/C di BPTU-HPT sudah sangat baik.S/C yang rendah merupakan faktor ekonomis yang sangat baik dan sangat berarti dalam perkawinan alam maupun IB (Salisbury dan Vandemark, 1985). Selanjutnya juga dinyatakan bahwa pada sapi betina berusia 4-6 tahun mempunyai nilai $\mathrm{S} / \mathrm{C}$ 
yang rendah dengan tingkat fertilitas yang stabil dan nilai $\mathrm{S} / \mathrm{C}$ akan tinggi pada ternak sejalan dengan menurunnya fertilitas.

Hasil perhitungan Chi-square terhadap nilai S/C bahwa S/C sapi aceh di BPTU-HPT indrapuri pada tahun 2017 dan 2018 tidak berbeda nyata $(P \geq 0,05)$. Hal ini disebabkan oleh faktor kesuburan ternak, waktu IB, kualitas semen, petugas IB dan pelaksanaan IB dan keterampilan inseminator dalam melaksanakan IB sudah cukup baik karena seringnya mengikuti pelatihan.

\section{Conception Rate(CR)}

Conceptionrate (CR) yaitu persentase sapi betina yang bunting pada inseminasi pertama yang disebut juga sebagai angka konsepsi. Conception rate ditentukan berdasarkan hasil pemeriksaan kebuntingan yang dilakukan oleh Dokter Hewan atau Petugas PKB (Toelihere, 1993). Kesuburan pejantan, kesuburan betina dan teknik inseminasi merupakan faktor penentu CR (Toelihere, 1981).

Tabel 2. Data Pemeriksaan Kebuntingan

\begin{tabular}{|c|c|c|c|c|}
\hline \multirow{2}{*}{ No } & \multirow{2}{*}{ Tahun } & \multirow{2}{*}{$\begin{array}{l}\text { Jumlah } \\
\text { Ternak }\end{array}$} & \multicolumn{2}{|c|}{$\begin{array}{c}\text { Pemeriksaan } \\
\text { Kebuntingan }\end{array}$} \\
\cline { 4 - 5 } & & & Positif & Negatif \\
\hline 1 & 2017 & 19 & 17 & 2 \\
\hline 2 & 2018 & 22 & 19 & 3 \\
\hline
\end{tabular}

Ket. Pemeriksaan Kebuntingan Ternak dilakukan 3 bulan setelah di IB

Angka kebuntingan atau conception rate ternak sapi yang dicapai di BPTU-HPT Indrapuri tahun 2017 dengan jumlah ternak 19 ekor adalah $89,47 \%$ sedangkan CR tahun 2018 dengan jumlah ternak 22 ekor adalah $86,36 \%$. Nilai CR yang didapat pada tahun 2017 dan 2018 di BPTU-HPT Indrapuri memiliki nilai cukup tinggi jika dibandingkan dengan penelitian yang dilakukan Irmanda (2018) CR sebesar 70,28\% yang dilakukan di Kecamatan Suka Makmur Kabupaten Aceh Besar.
Ternak yang mempunyai tingkat kesuburan tinggi, conception rate bisa mencapai $60 \%$ sampai $70 \%$ dan apabila CR setelah inseminasi pertama lebih rendah dari $60 \%$ sampai $70 \%$ berarti kesuburan ternak terganggu atau tidak normal (Wiryosuharto,1990). Pemeriksaan kebuntingan di BPTU-HPT Indrapuri dilakukan oleh Dokter Hewan dan Pengawas Bibit Ternak yang memiliki keahlian khusus yang dibuktikan dengan sertifikat keahlian reproduksi (IB,PKB,ATR dan TE). Menurut Hardjopranjoto (1995) efisiensi reproduksi pada sapi dianggap baik apabila CR dapat mencapai 65 - 75 persen. Teknik inseminasi yang digunakan oleh petugas IB pada penelitian ini adalah rectovaginal. Teknik ini akan menghasilkan CR yang tinggi Hardjopranjoto (1995).

CR dipengaruhi oleh bebeapa faktor penting yaitu ketepatan deteksi berahi, keterampilan petugas dala mmelaksanakan IB, kualitas semen, kondisi organ reproduksi betina dan manajemen pemeliharaan.

Hasil perhitungan uji $\mathrm{Z}$ terhadap rata-rata nilai $C R$ pada tahun 2017 dan 2018 di BPTU-HPT tidak menunjukkan perbedaan yang nyata.

\section{KESIMPULAN}

Dari hasil analisa data yang diperoleh dapat disimpulkan bahwa evaluasi hasil inseminasi buatan pada sapi aceh di BPTU-HPT Indrapuri menunjukkan bahwa rata-rata S/C pada tahun 2017 adalah 1,12 dengan rata-rata CR $89.47 \%$ sedangkan rata-rata nilai S/C pada tahun 2018 adalah 1,16 dengan CR $86,36 \%$ dimana hasil ini lebih baik dan lebih tinggi dari rata-rata. Hasil pengujian terhadap rata-rata nilai $\mathrm{S} / \mathrm{C}$ dan rata-rata nilai $\mathrm{CR}$ tidak menunjukkan perbedaan yang nyata. 


\section{DAFTAR PUSTAKA}

Hardjopranjoto. 1995. Ilmu Kemajiran pada Ternak. Airlangga University Press, Surabaya.

Irmanda, R. 2017. Evaluasi Keberhasilan Program Inseminasi Buatan di Kecamatan Suka Makmur Kabupaten Aceh Besar. Skripsi Program Studi Peternakan, Fakultas Pertanian, Universitas Syiah Kuala.

Sudjana.1992. Metode Statistika Edisi ke 5. Tarsito, Bandung.

Salisbury G. W. Dan Vandemark N. L. 1985.Fisiologi Reproduksi dan Inseminasi Buatan pada Sapi. Alih bahasa Djanuar R. Gadjah Mada University Press, Jogjakarta.

Toelihere M. R. 1981. Inseminasi Buatan pada Ternak. Angkasa, Bandung.

Toelihere M. R. 1993. Inseminasi Buatan pada Ternak. Angkasa, Bandung.

Wiryosuharto, D. S. 1990. Teknik dan Pengembangan Peternakan. Buletin Peternakan Jakarta. 